\title{
Laser-induced contamination of space borne laser systems: impact of organic contamination and mitigation by oxygen
}

\author{
M. Hippler ${ }^{\mathrm{a}}$, P. Wagner ${ }^{\mathrm{a}}$, H. Schroeder ${ }^{\mathrm{a}}$, W. Riede ${ }^{\mathrm{a}}$ \\ ${ }^{\mathrm{a}}$ German Aerospace Center (DLR), Institute of Technical Physics, \\ Pfaffenwaldring 38-40, 70569 Stuttgart
}

\begin{abstract}
Laser-induced contamination (LIC) is still a major risk for space based laser systems. In this paper the mitigation of LIC by oxygen is investigated. Tests were performed with a pulsed laser at $355 \mathrm{~nm}$. The partial pressure of the contamination material was in the range of $10^{-5}-10^{-4}$ mbar. The mitigation effect showed a threshold behavior concerning the ratio between contamination and oxygen pressure. Also a cleaning effect was successfully demonstrated: previously created depositions were completely removed by irradiation at several tens $\mathrm{Pa}$ oxygen pressure without any remaining degradation of the optical surface.
\end{abstract}

Keywords: space borne lidar, laser-induced contamination, molecular contamination, mitigation by oxygen

\section{INTRODUCTION}

Within the framework of so-called "Living Planet Programme" the European Space Agency (ESA) is preparing ADMAeolus satellite mission with a newly developed LIDAR system (ALADIN). Objective of the ADM-Aeolus mission is the measurement of global wind profiles for verification and improvement of current climate models [1,2]. A main part of ALADIN is a pulsed UV laser with up to $120 \mathrm{~mJ}$ pulse energy. Due to inevitable outgassing of organic materials which are integrated in the satellite and laser system a high risk of laser-induced contamination has to be considered [36]. LIC is mainly induced by molecular contamination and it describes the cumulative buildup of individual molecules on optical components due to the interaction of intense laser light with volatile molecules. LIC proved to be particular critical if the laser system is operated under vacuum conditions and in short wavelength regime (UV). Enhanced energy absorption on LIC deposits could drastically increase the vulnerability of the optics [7]. In former work it was shown, that deposit formation can be significantly reduced by oxygen [8]. In this paper more detailed investigations on this subject are presented. The ratio between oxygen and contamination material was varied in a wide range and the mitigation effect of oxygen was studied in-situ by long distance microscopy and fluorescence measurement. Adjustment and monitoring of the gas composition in the test chamber was realized by a differentially pumped residual gas analyzing system.

\section{TEST SETUP}

The experimental setup is designed to investigate LIC phenomena under realistic space conditions. A sketch of the setup is shown in Figure 1. Laser source is a pulsed Nd:YAG (1064 nm). By SHG and THG crystals (LBO) the infrared light is converted to $355 \mathrm{~nm}$. Pulse duration is $10 \mathrm{~ns}$ and repetition rate is up to $1 \mathrm{kHz}$. An attenuator consisting of half-wave plate and thin film polarizer is used for pulse energy adjustment. The test bench can be used both for investigation of optics in transmission or reflectance mode. For calculation of transmission or reflection values small portions of the

Systems Contamination: Prediction, Control, and Performance 2016, edited by Joanne Egges,

Carlos E. Soares, Eve M. Wooldridge, Proc. of SPIE Vol. 9952, 99520N · @ 2016 SPIE

CCC code: $0277-786 X / 16 / \$ 18 \cdot$ doi: $10.1117 / 12.2236897$

Proc. of SPIE Vol. $995299520 \mathrm{~N}-1$ 
entrance and exit beams are coupled out by wedges and online monitored with pulse energy detectors. The initial beam can be split into four beams with almost identical beam profiles and pulse energies. By this, up to three samples can be investigated simultaneously. The fourth beam is used as a reference. Entrance and exit windows are heated to $150{ }^{\circ} \mathrm{C}$ and the entrance beams are focused by lenses with long focal lengths. Both of these measures suppress laser-induced contamination on the windows. The UV beam profile is nearly Gaussian with a $1 / \mathrm{e}^{2}$ diameter of $250 \mu \mathrm{m}$ at the position of the entrance face of the optical samples.

The vacuum chamber consists of CF (ConFlat) components, sealed by copper gaskets. The central chamber contains the mounts for the optical samples and inspection windows for in-situ observation of fluorescence and for long-distance microscopy. A small chamber, used as contamination source is connected by a needle valve to the main chamber. It can be heated to increase the outgassing rate of the inserted contamination material. The needle valve allows an adjustment of the partial pressure of the contamination material within the main chamber. An oxygen gas supply is connected to the main chamber via a needle valve. A differentially pumped chamber is used for residual gas analyzing (RGA). It is connected via a gate valve to the main chamber. By the RGA the composition and partial pressures of the contamination constituents and of the added gas can be measured. The differential pumping allows the monitoring and adjustment of defined ratios between oxygen and contamination material up to a total pressure of $100 \mathrm{~Pa}$ in the main chamber. Vacuum pumping is performed by an oil free scroll pump and a turbo molecular pump. Pirani, penning and capacitance manometers are used for pressure sensing. The background pressure is better than $10^{-9} \mathrm{mbar}$.

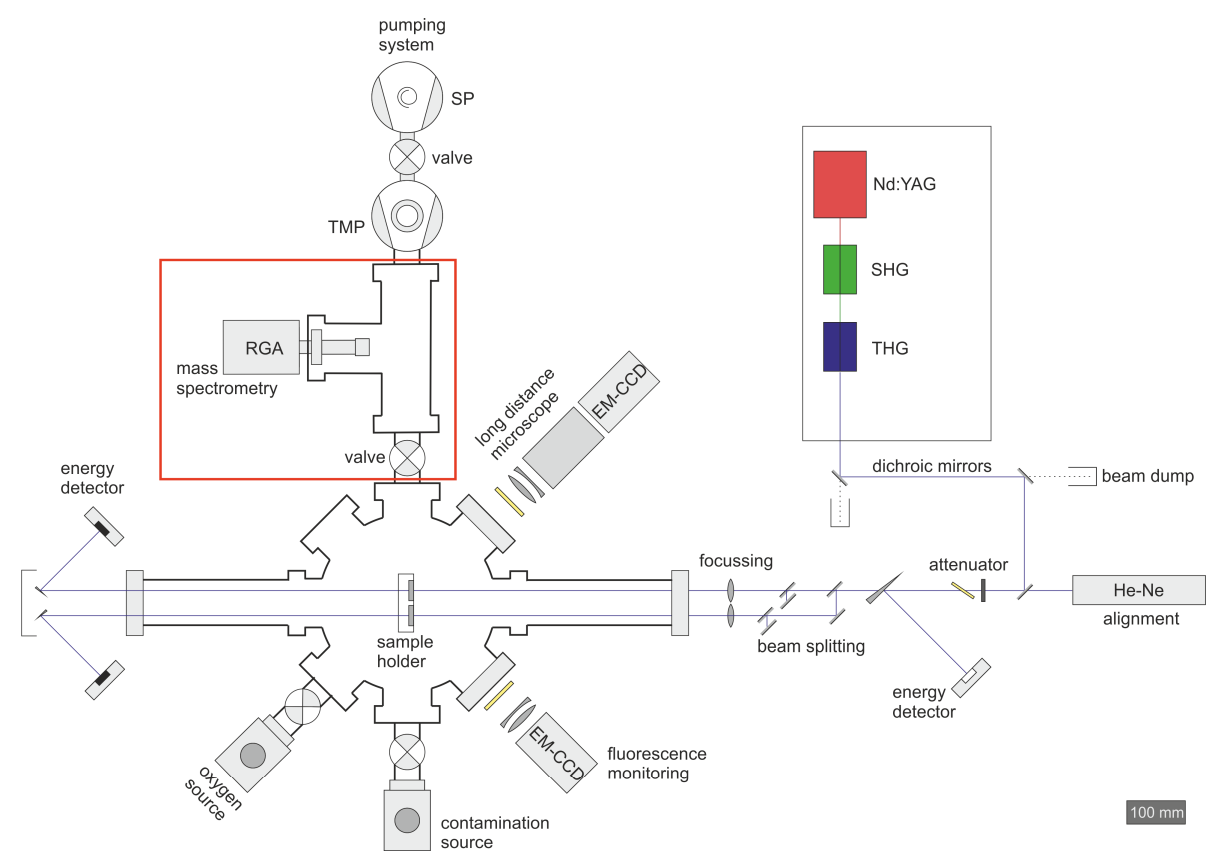

Figure 1: Laser-induced contamination test bench with ultra-high vacuum chamber, differentially pumped RGA system (red frame) and UV beam.

In former work it was shown, that laser-induced fluorescence (LIF) imaging is a sensitive tool to monitor the contamination growth and its dynamic on the optical samples $[9,10]$. The fluorescence signal from the optics surface is captured with a camera which is equipped with thermoelectric cooled $\left(-20^{\circ} \mathrm{C}\right)$ and electron multiplied CCD chip (EMCCD). One camera is installed on a computer controlled translation stage to investigate the fluorescence on different 
samples sequentially. A second EM-CCD camera is used together with a long distance microscope (LDM). It has a resolution down to $10 \mu \mathrm{m}$. The LDM-EMCCD is also used in combination with a flash lamp to characterize morphological changes of the surface and to monitor the deposition process. Interference effects from scattered UV light are prevented by proper edge filters.

Optical samples were inspected after the irradiation process by different ex-situ methods. The characterization of the surface is done by differential interference contrast microscope (DIC) and fluorescence microscope. White light interference microscopy (WLIM) is used for height measurements of deposited or ablated structures.

\section{RESULTS}

\subsection{LIC tests with naphthalene contaminant}

Naphthalene, a material with high vapor pressure $\left(4 \mathrm{~Pa}\right.$ at $\left.20^{\circ} \mathrm{C}\right)$ was chosen for fast and reproducible simulation of a stable contamination atmosphere. It is an aromatic hydrocarbon composed of two benzene rings. The molecular weight is $128 \mathrm{amu}$.

The contamination chamber was heated to $45^{\circ} \mathrm{C}$ during the tests. The peak fluence was varied between 0.3 and $1 \mathrm{~J} / \mathrm{cm}^{2}$. This is the relevant range for the laser system in the upcoming ESA mission ADM-Aeolus. The partial pressure of the contamination material was fixed to $10^{-5} \mathrm{mbar}$ or $10^{-4} \mathrm{mbar}$. It should be noted, that even a contamination pressure of $10^{-}$ ${ }^{5}$ mbar is at least one magnitude higher than what is expected in space systems. Therefore, the tests reported here present a worst case scenario.

The oxygen-naphthalene ratio was varied between 0:1 and 4000:1, resulting in maximum oxygen pressure of $4 \times 10^{-2}$ mbar (4 Pa) resp. $4 \times 10^{-1} \mathrm{mbar}(40 \mathrm{~Pa})$. An overview of the test parameters is given in Tab. 1 .

\begin{tabular}{|ll|}
\hline Parameter & Value \\
\hline Fluence $\left[\mathrm{J} / \mathrm{cm}^{2}\right]$ & $0.3 ; 0.6 ; 1.0$ \\
Absolute naphthalene pressure [mbar] & $10^{-5} ; 10^{-4}$ \\
Oxygen-naphthalene ratio & $0: 1 ; 10: 1 ; 50: 1 ; 100: 1 ; 1000: 1 ; 4000: 1$ \\
Repetition rate $[\mathrm{kHz}]$ & $0.1 ; 1.0$ \\
\hline
\end{tabular}

Table 1: Overview of test parameters of the LIC mitigation experiments with naphthalene as contaminant

Fig. 2 shows the final transmission values for AR optics, coated by magnetron sputtering after $3.6 \times 10^{6}$ laser pulses in dependence on the oxygen-naphthalene ratio. There is a clear evidence for a threshold behavior. The red lines show fitting curves to the experimental data. The fit function is $\mathrm{f}(\mathrm{x})=\mathrm{A}+(\mathrm{B}-\mathrm{A}) /\left(1+\left(\mathrm{x} / \mathrm{x}_{\mathrm{T}}\right)^{2}\right)$, which is commonly used for description of threshold effects. For ratios higher than 50:1 the LIC effect is drastically reduced and for ratios larger than 1000:1 no transmission loss was detectable within the limits of accuracy. 


\section{Naphthalene pressure}

\section{$10^{-5} \mathrm{mbar}\left(10^{-3} \mathrm{~Pa}\right)$}
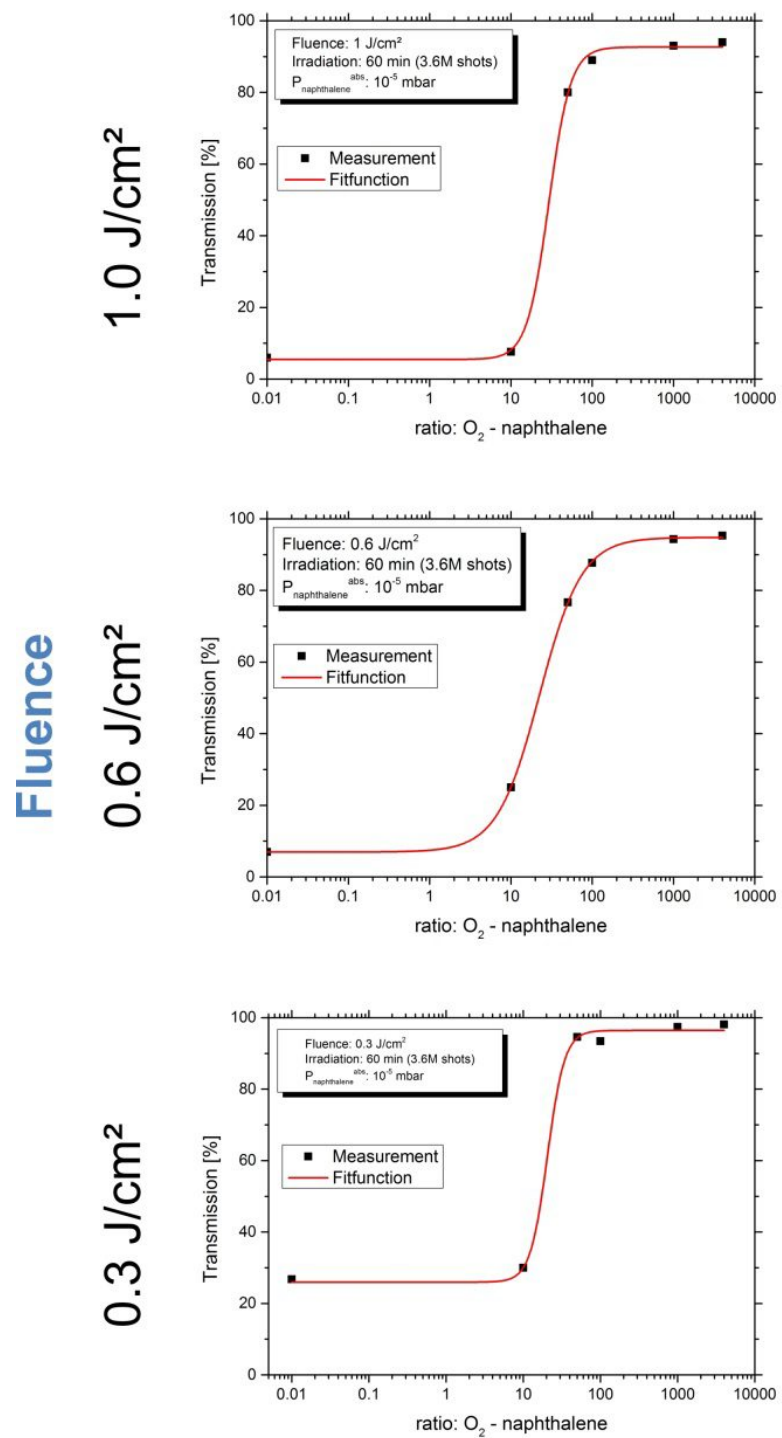

$10^{-4}$ mbar $\left(10^{-2} \mathrm{~Pa}\right)$
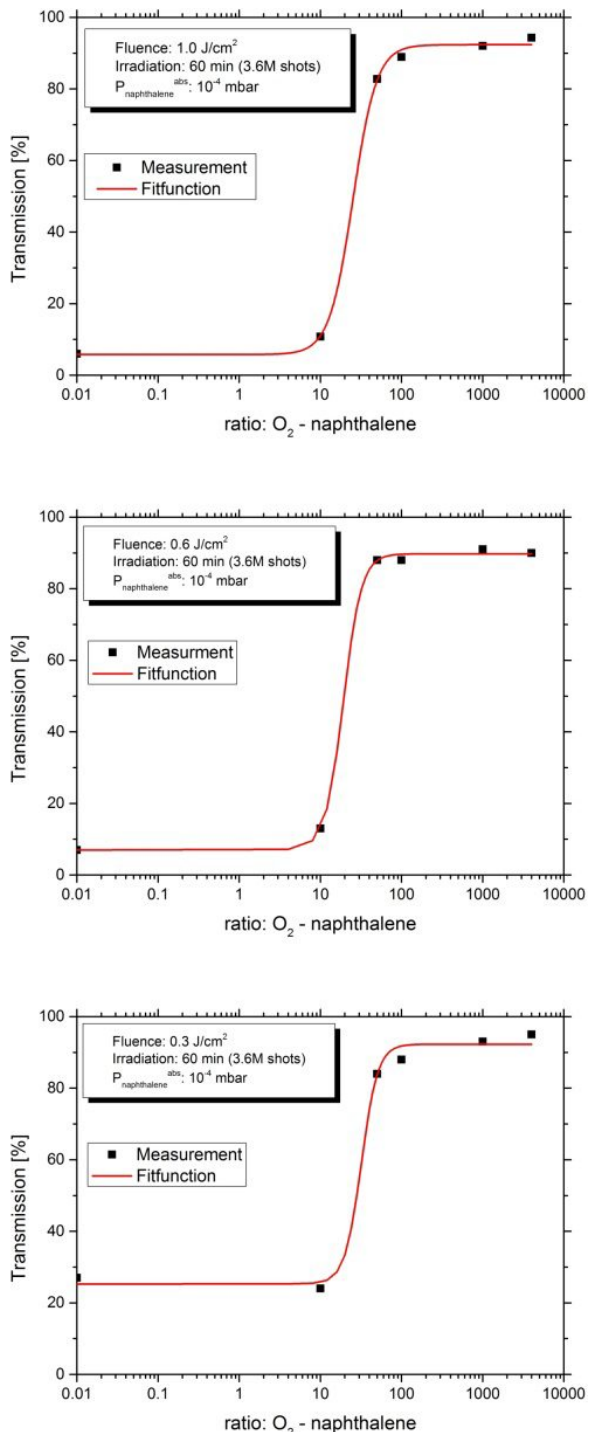

Figure 2: Transmission values after irradiations for 3.6 M shots under various oxygen-naphthalene ratios. Optical samples were AR coated on both sides by magnetron sputtering. The tests were run at $1 \mathrm{kHz}$ repetition rate.

The oxygen threshold behavior is also observed by ex-situ inspection of the optical samples with differential interference contrast (DIC) microscopy (Fig. 3). For low oxygen-naphthalene ratios a damage i.e. ablation of the coating within the irradiated area was observed. The ablation area is getting smaller with increasing oxygen-naphthalene ratio and no ablation was observed above a ratio of 100:1. In blank tests at high vacuum without any naphthalene no damage at all was observed for this fluence. This means, that the damage is caused by laser-induced contamination and that the observed reduction in damage with increasing oxygen concentration is also a clear sign for a reduction of contamination 
growth on the optical surface. However, at the highest ratio of 4000:1 within the test series with naphthalene only a faint deposition in the low nm range is determined.

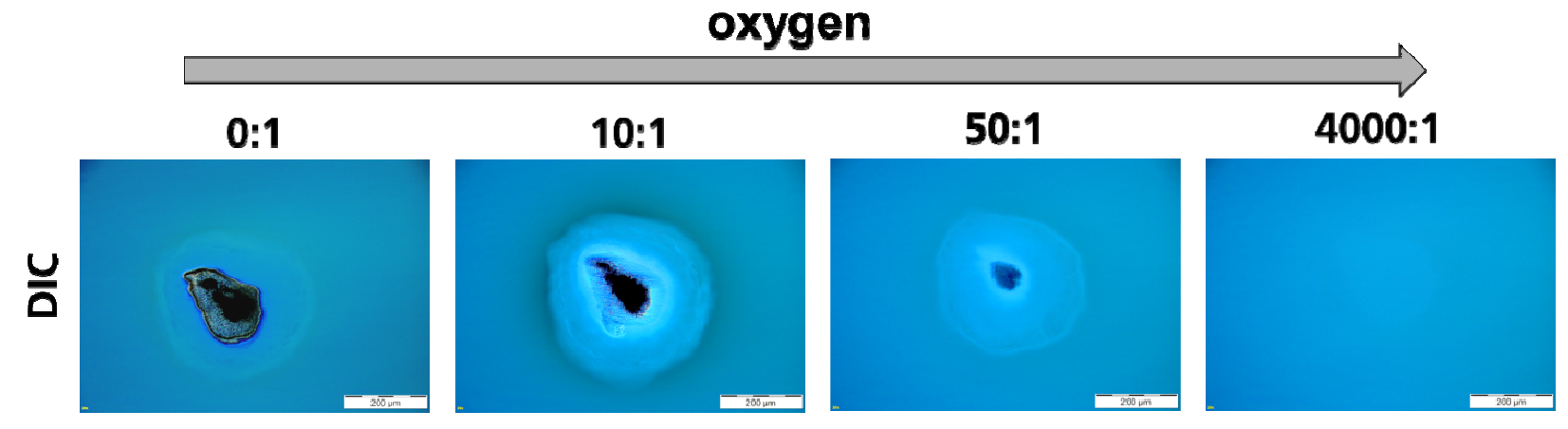

Figure 3: DIC micrographs of the entrance faces of optical samples after irradiations for $3.6 \mathrm{M}$ shots at $1 \mathrm{~J} / \mathrm{cm}^{2}$, a naphthalene pressure of $10^{-5} \mathrm{mbar}$ and various oxygen-naphthalene ratios between 0:1 and 4000:1. Optical samples were AR coated by magnetron sputtering.

To investigate the long term performance of the oxygen influence one test was run for $6 \mathrm{~h}$ at $1 \mathrm{kHz}$, which corresponds to an overall shot number of $21 \mathrm{M}$ shots. Additional, a $3 \mathrm{~h}$ test at $100 \mathrm{~Hz}$ (1M shots) was performed. Both experiments were run at similar conditions with peak fluence of $1 \mathrm{~J} / \mathrm{cm}^{2}$, an oxygen-naphthalene ratio of 4000:1, and a partial contamination pressure of $1 \times 10^{-5}$ mbar. Optical samples were fused silica with magnetron sputtered AR coatings. For both tests a similar mitigation effect and no difference to blank tests was observed (Fig. 4).

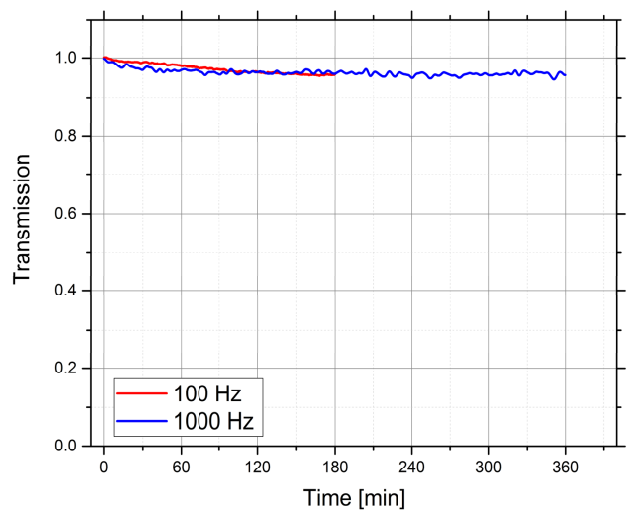

Figure 4: Prevention of LIC by oxygen. Partial pressure of contaminant: $10^{-5}$ mbar naphthalene. $\mathrm{O}_{2}$ pressure: $4 \times 10^{-2}$ mbar. Fluence: 1 $\mathrm{J} / \mathrm{cm}^{2}$. Optical samples: Fused silica with magnetron sputtered AR coatings.

Results of the 3M-shot tests with e-beam deposited (EBD) AR coatings are similar to those with the MS coatings. But during the test with higher pulse numbers ( $21 \mathrm{M}$ shots), the EBD sample showed a significant higher transmission loss than the MS coated sample. Fig. 5 shows the results of tests with $1 \mathrm{kHz}$ repetition rate, a fluence of $1 \mathrm{~J} / \mathrm{cm}^{2}$, a naphthalene partial pressure of $10^{-5} \mathrm{mbar}$ and an oxygen pressure of $4 \times 10^{-2} \mathrm{mbar}(4 \mathrm{~Pa})$. By WLIM inspection ablation of about $30 \mathrm{~nm}$ was determined in the high fluence area on the EBD coated sample and no ablation effect could be 
determined for the sample with the MS coating process. Possibly the LIC effect is enhanced by the higher porosity of the EBD coating. This behavior was also observed in former experiments with AR coated optics [7].

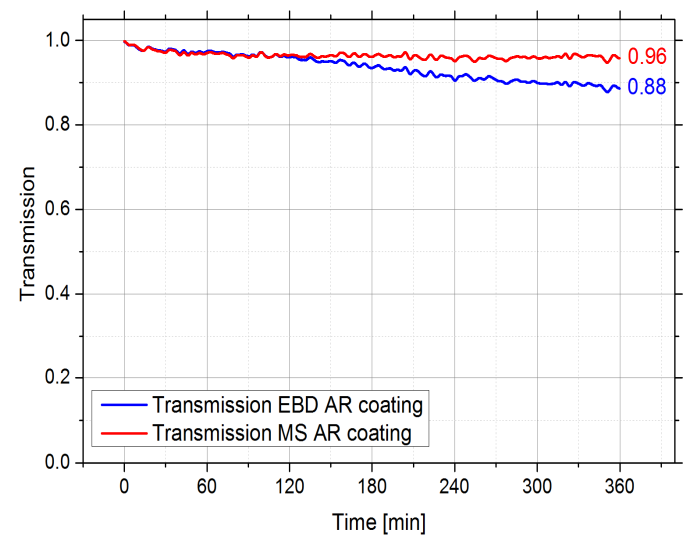

Figure 5: Comparison of the in-situ transmission for MS and EBD AR coated samples. Both samples were irradiated simultaneously under identical conditions. Repetition rate: $1 \mathrm{kHz}$, fluence: $1.0 \mathrm{~J} / \mathrm{cm}^{2}$, partial pressure of contaminant: $10^{-5} \mathrm{mbar}$ naphthalene, oxygen pressure: $4 \times 10^{-2} \mathrm{mbar}(4 \mathrm{~Pa})$.

\subsection{Space relevant contaminants}

All tests discussed above were performed with naphthalene. In this section experiments with a mixture of different materials which are used for space borne applications will be discussed. These materials (electrical connectors, isolation materials, cable ties, tapes, shrinking tubes etc.) and they were placed at our disposal by ESA/ESTEC. With these materials a test sequence consisting of LIC deposition, cleaning by oxygen and lifetime test (1G shot) was performed. The initial LIC deposition was run without oxygen at $1 \mathrm{~J} / \mathrm{cm}^{2}$ for $1.4 \mathrm{M}$ shots at $100 \mathrm{~Hz}$. The partial pressure of the contamination materials was in the range of $10^{-4}$ mbar. The deposition growth was observed by in-situ fluorescence measurement. It showed the typical transition from so-called "pancake" to "donut" growth (Fig. 6) known from similar tests reported elsewhere [11]. The in-situ fluorescence signal increases for the complete deposition phase with increasing pulse number (Fig. 8, black squares). This means that the thickness of the LIC deposit increases [9,10]. By in-situ microscopy it was proved, that no surface damage occurred. Subsequently a cleaning process was performed. Therefore the deposit was irradiated at $1 \mathrm{~J} / \mathrm{cm}^{2}$ with $1.6 \mathrm{M}$ shots in air atmosphere of $80 \mathrm{~Pa}$. The partial pressure of contamination material was the same as during LIC deposition $\left(10^{-4} \mathrm{mbar}\right)$. The ratio between oxygen and contamination material was in the range of 1600. During irradiation the fluorescence intensity of the donut shaped deposition is decreasing (Fig 7). The cleaning rate is rather strong at the beginning and after 0.6 M pulses it slows down (Fig. 8, red dots). At the end of the cleaning process only faint fluorescence was observed. Finally a life time test $(280 \mathrm{~h}, 1 \mathrm{G}$ shot $)$ at low oxygen pressure $(0.3 \mathrm{mbar})$ and $10^{-4} \mathrm{mbar}$ of contamination was performed on the recovered position. The fluence was $1 \mathrm{~J} / \mathrm{cm}^{2}$ and a repetition rate of $1 \mathrm{kHz}$ was chosen in order to accelerate the test. At the beginning of the lifetime test the partial oxygen pressure was adjusted to $30 \mathrm{~Pa}$ simultaneously with $10^{-4}$ mbar contamination. Oxygen pressure remained constant over the irradiation time of $280 \mathrm{~h}$. The intensity of fluorescence was very low for the entire duration of the lifetime test and no deposits on the irradiated surface were detectable (Fig. 8, blue triangles). Ex-situ inspection of the optical sample by DIC and scanning electron microscopy showed no damage. Neither micro sized defects nor any surface change was observed. 

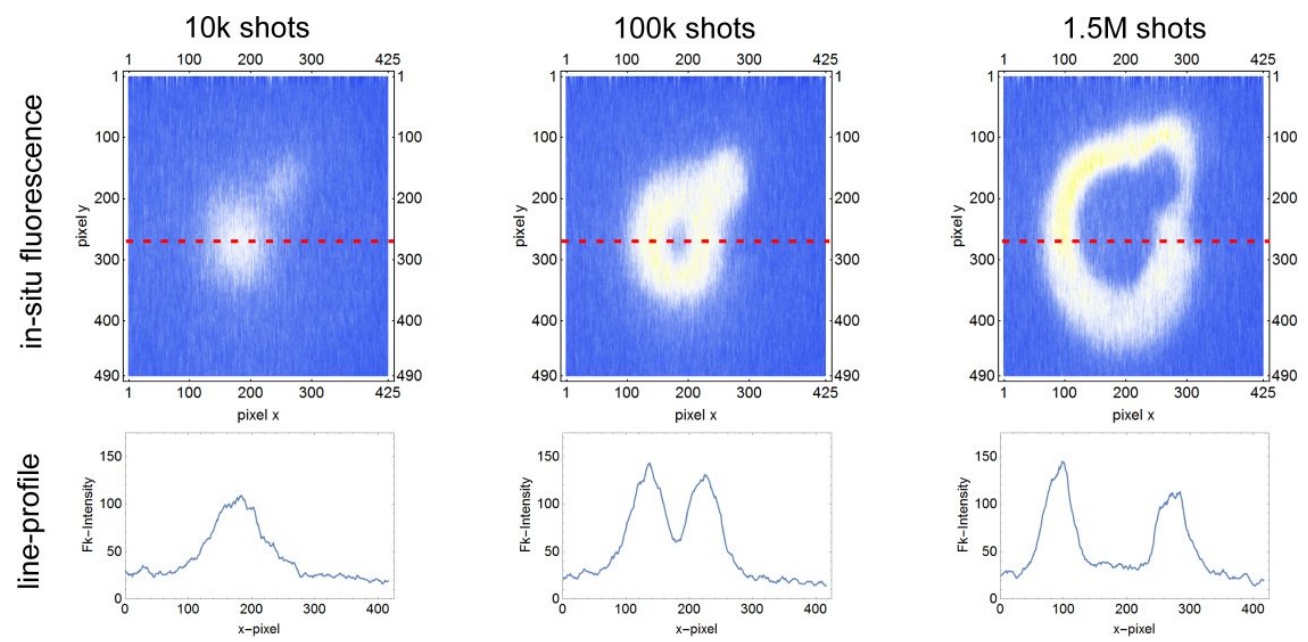

Figure 6: In-situ taken LDM micrographs showing fluorescence intensity during laser-induced contamination growth prior to the lifetime test. Irradiation was performed with a fluence of $1 \mathrm{~J} / \mathrm{cm}^{2}$ and an absolute contamination pressure of $10^{-4}$ mbar using a mixture of space relevant contamination materials. Test was run without oxygen. Fluorescence intensity line-profiles were taken at the positions marked by red dotted lines. 1 Pixel corresponds to $1 \mu \mathrm{m}$.
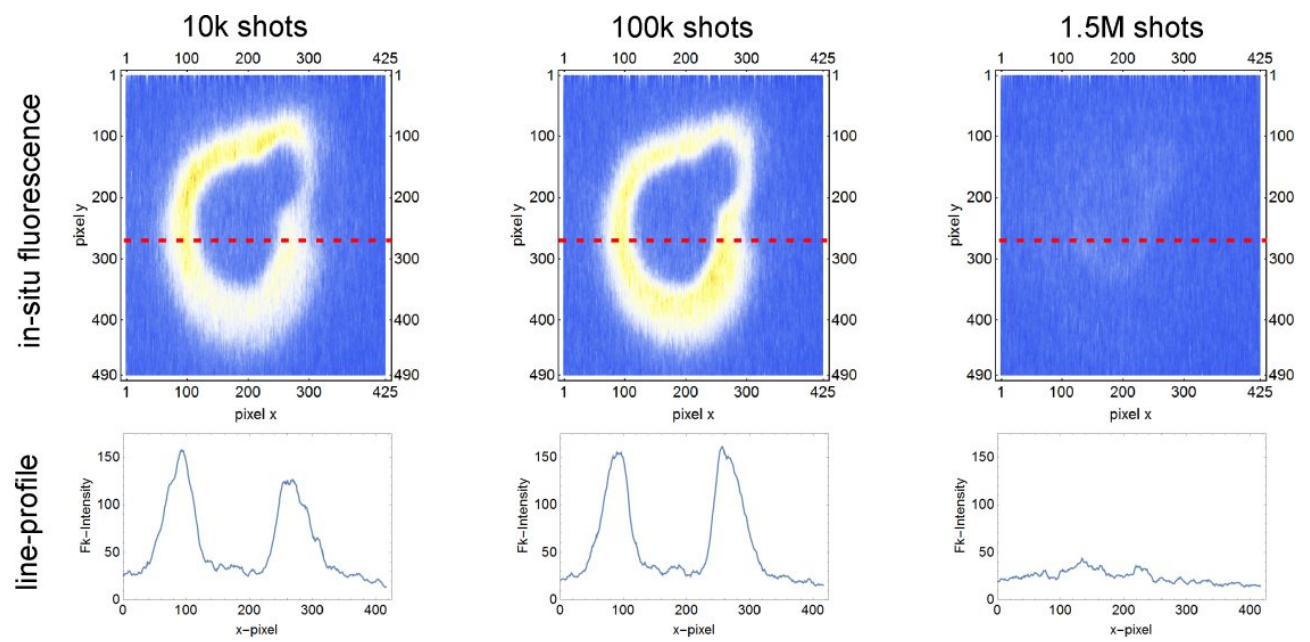

Figure 7: Removal of a deposition by UV irradiation in $80 \mathrm{~Pa}$ air atmosphere. The fluence was $1 \mathrm{~J} / \mathrm{cm}^{2}$ and the partial pressure of the contamination material was $10^{-4}$ mbar. 


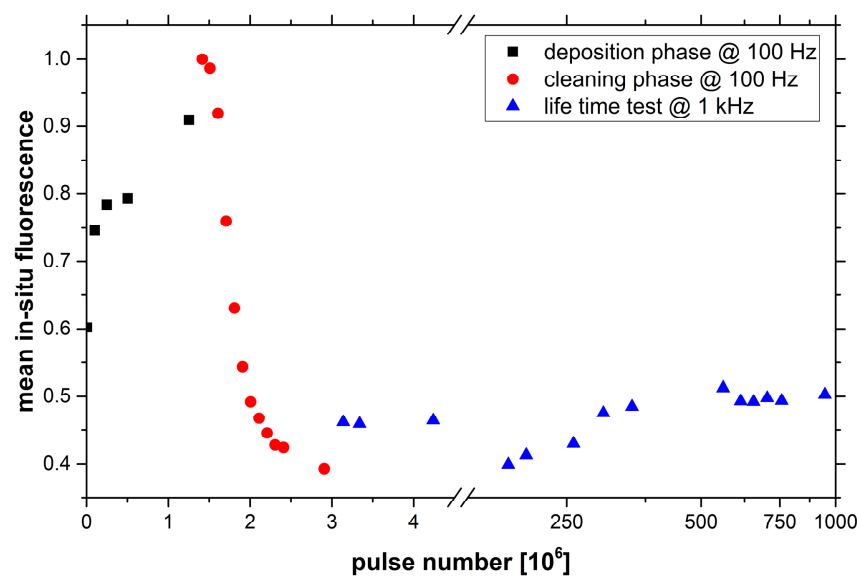

Figure 8: Mean in-situ fluorescence intensity for test sequence with LIC deposition, cleaning and lifetime test. Deposition was run without oxygen. Cleaning and lifetime test were run in air atmosphere of $80 \mathrm{~Pa}$. Fluence: $1 \mathrm{~J} / \mathrm{cm}^{2}$, partial pressure of contamination: $10^{-4}$ mbar.

\section{SUMMARY}

We reported in this paper on the mitigation of laser-induced contaminations by oxygen. It was shown that for UV fluences between 0.3 and $1.0 \mathrm{~J} / \mathrm{cm}^{2}$ and partial pressures of contamination in the range between $10^{-4}$ and $10^{-5} \mathrm{mbar}$ the formation of depositions can be nearly completely inhibited by oxygen. Corresponding tests were run with naphthalene and space relevant contamination materials. The mitigation effect showed clear threshold behavior. It was also shown, that optical surfaces on which laser-induced depositions were initially formed could be recovered by irradiation in air atmosphere of $80 \mathrm{~Pa}$.

\section{ACKNOWLEDGEMENT}

The work was performed with kind support by ESA/ESTEC under contract No. 5001014920. The authors gratefully acknowledge Denny Wernham (ESA/ESTEC) for many helpful discussions. We would like to thank our staff members G. Taube and F. Hadinger for their support during tests and diagnostic of optical samples.

\section{REFERENCES}

1 M. Endemann, "The ADM-AEOLUS Mission"; Proc. '6th Internat. Conf. on Space Optics', ESTEC, Noordwijk, The Netherlands, ESA SP-621; 2006.

2 D. Morançais, L. Mazuray, J.-C. Barthès; "ALADIN, the first wind LIDAR in space: Development status", Proc. '6th Internat. Conf. on Space Optics', ESTEC, Noordwijk, The Netherlands, ESA SP-621; 2006

3 F. E. Hovis, B. A. Shepherd, C. T. Radcliffe, and H. A. Maliborski; "Contamination damage in pulsed $1 \mu \mathrm{m}$ lasers", Proc. of SPIE Vol. 2714, 707;1996. 
4 C. Scurlock, "A phenomenological study of contamination enhanced laser induced damage in sealed lasers", Proc. of SPIE Vol. 5647, 86; 2004

5 W. Riede, P. Allenspacher, H. Schröder, D. Wernham, Y. Lien; "Laser-induced hydrocarbon contamination in vacuum"; Proc. of SPIE Vol. 5991, 59910H-1; 2005.

6 H. Schröder, W. Riede, H. Kheyrandish, D. Wernham, Y. Lien; "Investigation of UV Laser Induced Depositions on Optics under Space Conditions in Presence of Outgassing Materials"; Proc. 6th International Conference on Space Optics, Noordwijk, The Netherlands; 2006.

7 H. Schröder, P. Wagner, D. Kokkinos, W. Riede, A. Tighe; "Laser-induced contamination and its impact on laser damage threshold", Proc. of SPIE 8885, 88850R; 2013.

8 A. P. Tighe, F. Pettazzi, J. Alves, D. Wernham, W. Riede, H. Schroeder, P. Allenspacher, H. Kheyrandish; "Growth mechanisms for laser induced contamination on space optics in vacuum". Proc. SPIE 7132, 71321L; 2008.

9 H. Schröder, S. Becker, Y. Lien, W. Riede, D. Wernham; "Fluorescence monitoring of organic deposits"; Proc. of SPIE Vol. 6720, 67200O-1; 2007.

10 H. Schröder, W. Riede, E. Reinhold, D. Wernham, Y. Lien, H. Kheyrandish; "In situ observation of UV laserinduced deposit formation by fluorescence measurement"; Proc. of SPIE Vol. 6403, 64031K-1; 2007.

11 H. Schroeder, S. Borgmann, W. Riede, D. Wernham, "Investigations of laser-induced deposit formation under space conditions", Proc. 7th Internat. Conf. on Space Optics, Toulouse France; 2008. 